\title{
A novel CYP11B1 mutation in a Turkish patient with $11 \beta$-hydroxylase deficiency: An association with the severe hypokalemia leading to rhabdomyolysis
}

\author{
Banu Sarer Yurekli, Nilufer Ozdemir Kutbay, Huseyin Onay, Ilgin Yildirim Simsir, \\ Gokcen Unal Kocabas, Mehmet Erdogan, Sevki Cetinkalp, Gokhan Ozgen, Fusun Saygili
}

Ege University Faculty of Medicine, Endocrinology Department, Bornova, Izmir, Turkey

Dear Sir,

Congenital adrenal hyperplasia $(\mathrm{CAH})$ is an autosomal recessive disorder caused by the loss of one of five steroidogenic enzymes affecting cortisol synthesis. Deficiency of 21-hydroxylase is the most common cause of $\mathrm{CAH}$, accounting for more than $90 \%$ of all cases; it is followed in frequency by $11 \beta$-hydroxylase deficiency (11ßOHD), reported to be between 3\% and $5 \%$ of cases. ${ }^{1}$ Kelestimur et al found that, based on 11-deoxycortisol response to ACTH stimulation, $6.5 \%$ of hirsute women in a Turkish population had $11 \beta O H D .^{2}$ The $11 \beta$-hydroxylase gene is located on chromosome 8q21-q22. In 11ßOHD, 11-deoxycortisol cannot be converted to cortisol, and deoxycorticosterone (DOC) cannot be converted to corticosterone. Enzyme inhibition stimulates ACTH secretion resulting in excess androgen and DOC. DOC, which is a less potent mineralocorticoid, causes hypokalemia

Key words: 11-B hydroxylase deficiency, Hypokalemia, Novel mutation

\footnotetext{
Address for correspondence:

Banu Sarer Yurekli, Ege University Faculty of Medicine,

Endocrinology Department, Izmir, Turkey;

Mobile phone: +90 5055250373, Fax: 903204784 ,

E-mail: bsareryurekli@yahoo.com

Received 29-11-2015, Accepted 27-12-2015
}

and hypertension. Two thirds of $11 \beta \mathrm{OHD}$ cases have hypertension. In the classical form of $11 \beta \mathrm{OHD}$, hypertension in both sexes, ambiguous genitalia in women and increased penile length with normal external genitalia and gynecomastia in men are observed. ${ }^{1} \mathrm{We}$ present a case of $11 \beta O H D$ with severe hypokalemia and in which we have found a novel mutation.

A 20-year-old male patient who had been on steroid replacement treatment for adrenal insufficiency for 18 years was admitted to our emergency department with spasms, dyspnea and syncope attacks. On admission, there was severe hypokalemia with a blood potassium level of $1.4 \mathrm{mEq} / \mathrm{L}$. The patient's history revealed a surgery due to ileus and high blood pressure levels. The other laboratory test results were as follows: AST: 358U/L, ALT: 163U/L, CK: 12740U/L, CKBM: $117 \mathrm{U} / \mathrm{L}$, creatinine: $0.81 \mathrm{mg} / \mathrm{dl}, \mathrm{Na}: 149 \mathrm{meq} / \mathrm{L}$, $\mathrm{K}: 1.4 \mathrm{meq} / \mathrm{L}$, myoglobin $>3000 \mathrm{ng} / \mathrm{ml}$, ACTH: 16.6 $\mathrm{pg} / \mathrm{mL}$, cortisol: $5.14 \mu \mathrm{g} / \mathrm{dL}$, fT3: $2.15 \mathrm{pg} / \mathrm{mL}$, fT4: $1.40 \mathrm{ng} / \mathrm{dL}$, TSH: $1.51 \mu \mathrm{IU} / \mathrm{ml}$, Total Testosterone: $3.44 \mathrm{ng} / \mathrm{mL}$ (1.75-7.81), Free Testosterone: $23.1 \mathrm{pg} /$ $\mathrm{mL}(8.69-54.69)$, DHEAS: $114.9 \mu \mathrm{g} / \mathrm{dL}, 17 \mathrm{OH}$ progesterone: $9.4 \mathrm{ng} / \mathrm{mL}$. High myoglobin and creatinine kinase $(\mathrm{CK})$ levels were indicative of rhabdomyolysis. $11 \beta O H D-r e l a t e d \mathrm{CAH}$ was suspected, as the patient had adrenal insufficiency and hypertension as well as resistant hypokalemia in spite of potassium intravenous infusion. Spironolactone treatment was started and, at follow-up, potassium levels were back to normal. The 
hypokalemia-related rhabdomyolysis regressed. Steroid treatment was reduced to the physiological replacement level. In the patient's genetic examination, "p.A199P (c. 595G >C) and p.R448H (c.1343G >A) compound heterozygous mutations" were detected in 11 beta hydroxylase (CYP11B1) whole genome sequencing analysis. This is of note, since p.A199P (c.595G >C) mutations have not previously been described in this clinical condition. This novel mutation was evaluated, via application of MutationTaster and SIFT in silico analysis software, as being a disease-causing mutation. It was shown by further sequencing of the parents that this novel mutation was inherited from the mother. The father was a carrier of the $\mathrm{p} \cdot \mathrm{R} 448 \mathrm{H}$ mutation (Figure 1A, B).

Herein we have described a case of $11 \beta \mathrm{OHD}$ with a compound heterozygous mutation presenting as severe hypokalemia. Approximately 90 different CYP11B1 gene mutations have been described in the literature. These mutations are located over the entire coding region generally accumulated in exons 2,6 , 7 and $8 .^{1-3}$ There is no correlation between a specific CYP11B1 gene mutation and the clinical picture of $11 \beta O H D$, since the same mutation can cause different clinical features with regard to onset of symptoms, age at diagnosis, severity of virilization and hypertension. ${ }^{1-3}$ According to in vitro studies, the $\mathrm{R} 448 \mathrm{H}$ mutation, which is very frequent among $11 \beta \mathrm{OHD}$ patients, completely impairs $11 \beta \mathrm{OH}$ enzyme activity. ${ }^{4}$ The second mutation found in our patient is the novel p.A199P mutation, which should result in a nonfunctional protein. Rosler reported 26 patients with $\mathrm{CAH}$ due to 11 beta hydroxylase deficiency
A

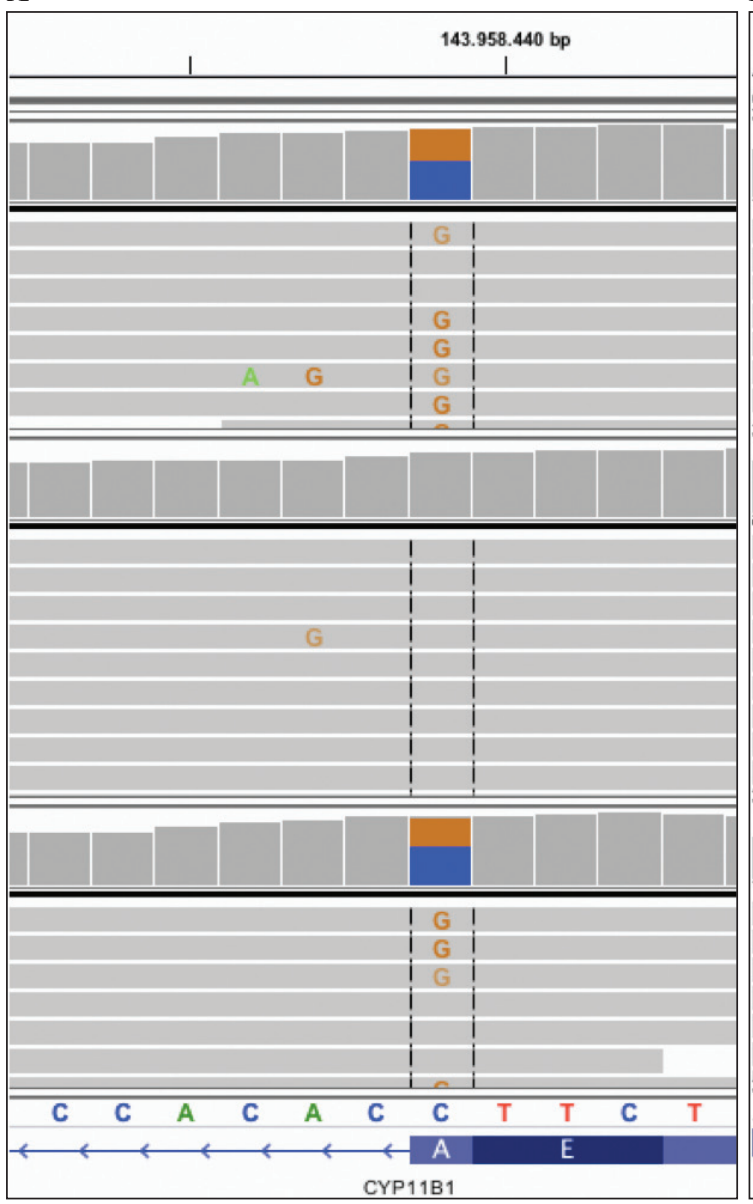

B

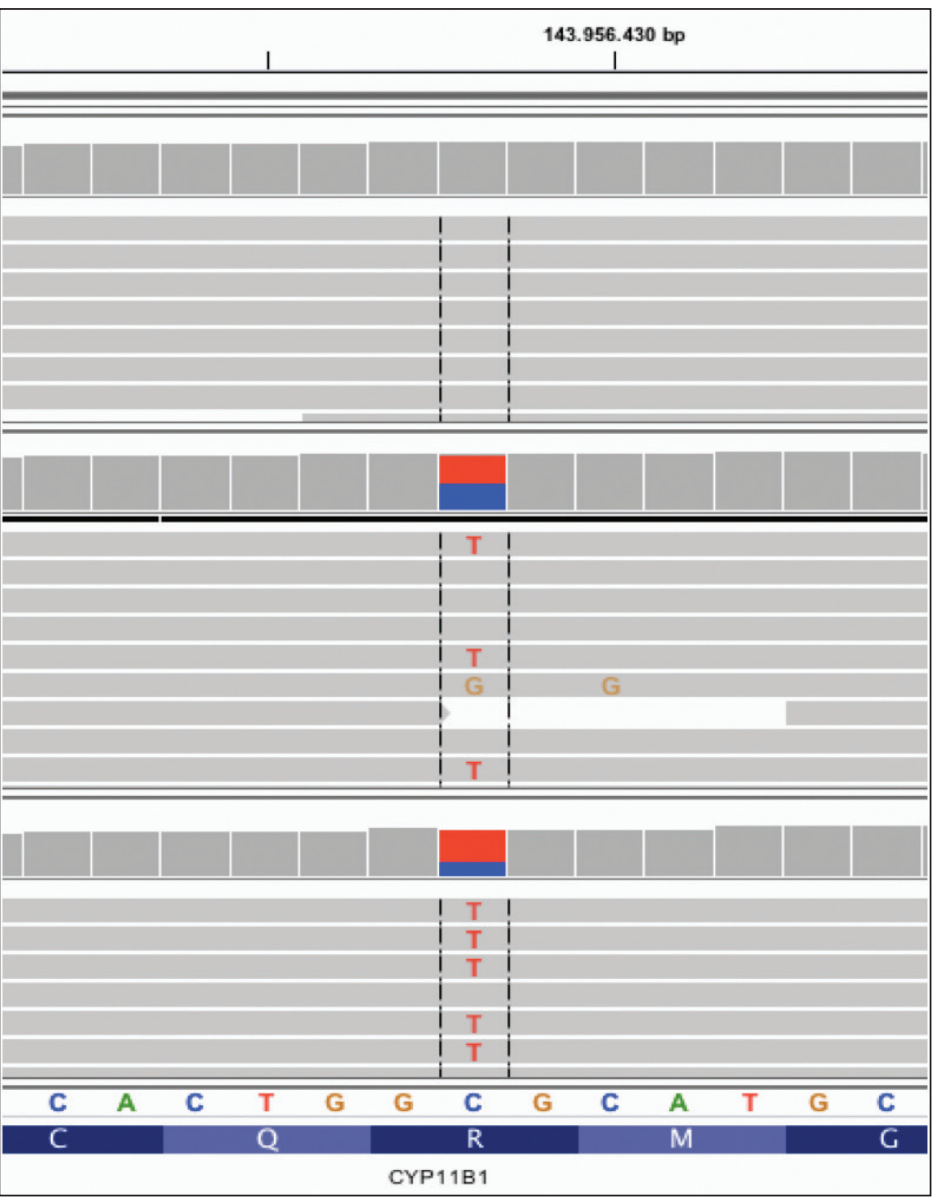

Figure 1.A: p.A199P (c.595G>C) mutation. Upper part for the mother of the patient, lower part for the patient. B: p.R448H (c.1343G>A mutation. Middle part for the father of the patient, lower part for the patient. 
identified in a study of 18 Jewish families. It was shown that the clinical picture of androgen excess varies from the mildest form to the most severe form of masculinization. In these patients, there was no correlation between androgen excess and mineralocorticoid excess. Overt hypokalemia was present in 6 out of the 26 patients. Even though very low plasma renin levels were present in almost all patients, high blood pressure was not always present. The clinical picture of this disorder shows great variability as to signs of mineralocorticoid and androgen excess. This condition is not invariably correlated with the levels of hormones. ${ }^{5}$ In our patient, we had no measurement of renin and 11-DOC concentrations, nor could we find any laboratory results relating to his past medical history. Nevertheless, our case suggests that the compound heterozygous p.A199P/R448H mutation may predict severe $\mathrm{CAH}$ phenotype regarding the degree of hypokalemia.

\section{CONFLICT OF INTEREST}

The authors do not have any conflict of interest.

\section{REFERENCES}

1. Speiser PW, White PC, 2003 Congenital adrenal hyperplasia. N Engl J Med 349: 776-788.

2. Kelestimur F, Sahin Y, Ayata D, Tutus A, 1996 The prevalence of non-classical adrenal hyperplasia due to 11 beta-hydroxylase deficiency among hirsute women in a Turkish population. Clin Endocrinol (Oxf) 45: 381-384.

3. Nimkarn S, New MI, 2008 Steroid 11 beta-hydroxylase deficiency congenital adrenal hyperplasia. Trends Endocrinol Metab 19: 96-99.

4. Curnow KM, Slutsker L, Vitek J, et al, 1993 Mutations in the CYP11B1 gene causing congenital adrenal hyperplasia and hypertension cluster in exons 6,7, and 8. Proc Natl Acad Sci U S A 90: 4552-4556.

5. Rosler A, Leiberman E, Sack J, et al, 1982 Clinical variability of congenital adrenal hyperplasia due to 11 beta-hydroxylase deficiency. Horm Res 16: 133-141. 